\title{
Dilemma in the foreign lands during COVID-19: An outlook of expat health care professionals with a take on a social perspective
}

\author{
Namdeo Prabhu ${ }^{\mathrm{a}}$ and Rakhi Issrani ${ }^{\mathrm{b}, *}$ \\ ${ }^{a}$ Department of Oral and Maxillofacial Surgery and Diagnostic Sciences, College of Dentistry, Jouf University, \\ Sakaka, Kingdom of Saudi Arabia \\ ${ }^{\mathrm{b}}$ Department of Preventive Dentistry, College of Dentistry, Jouf University, Sakaka, Kingdom of Saudi Arabia
}

Received 9 July 2020

Accepted 25 September 2020

\begin{abstract}
.
BACKGROUND: The World Health Organization (WHO) has declared novel coronavirus (COVID-19) infection a global pandemic due to the fast transmission of this disease worldwide. To prevent and slow the transmission of this contagious illness, the public health officials of many affected countries scrambled to introduce measures aimed at controlling its spread. As a result, unprecedented interventions/measures, including strict contact tracing, quarantine of entire towns/cities, closing of borders and travel restrictions, have been implemented by most of the affected countries including the Kingdom of Saudi Arabia.

OBJECTIVE: The aim of this paper is to share health care professionals' perspectives who are experiencing COVID19 firsthand in a foreign land. In addition, the role of the Saudi governance to combat the current situation is also discussed.

DISCUSSION: Personal and previous experiences as related to Middle East respiratory syndrome coronavirus (MERS-CoV) by the authors has been compared to the current situation and how it affected our thoughts and management. A review of the evidence-based literature was conducted to investigate the demographics of the region; and to understand the awareness of the various tools that are available and how they were utilized in the present situation of pandemic.
\end{abstract}

CONCLUSION: Saudi Arabia has been challenged during the pandemic as are other countries.

Keywords: Coronavirus, dental education, pandemic, Middle East, MERS-CoV

\section{Introduction}

With COVID-19 infection all set to become a household example of the modern times akin to plague, there is no better timing to disperse the thoughts and takes of this situation, especially for a health care professional who is experiencing it firsthand. On January

\footnotetext{
*Address for correspondence: Dr. Rakhi Issrani, Lecturer, Department of Preventive Dentistry, College of Dentistry, Jouf University, Sakaka, Kingdom of Saudi Arabia. Tel.: +966 568250031; E-mail: dr.rakhi.issrani00@gmail.com.
}

30, 2020, WHO declared the COVID-19 infection as a global pandemic [1]. As a dental professional and also as a citizen under lockdown, both have shaped my thoughts on dual horizons. The hope that modern medical science can conquer almost anything gets clouded over by the emotions that we face as a citizen. What is more frustrating is difficult to fathom; the desperation to overcome this plague or handling the sanctions on our freedom. Further twisting this disarray is the fact that educational sector has been affected in unprecedented way. Undoubtedly the pandemics 
impose devastating consequences on communities and exhibits long-term rippling effects in the economy and the health care system as well [2]. Never in the history of mankind, have we faced a global public health issue of this magnitude with its effect felt across a spectrum of activities encompassing economic, travel, governance and education [3].

Nevertheless, as our hope to binge in social intermingling does not seem to fade, we all have to work towards one common goal, to contain the virus and restoring the normalcy for the sake of a vivacious neighborhood. The aim of this paper is to discuss and understand the current situation of a health care professional in a foreign land. In addition, the role of the Saudi governance to combat this vicious infection has also been given a thought to.

\section{COVID-19 in the Kingdom of Saudi Arabia (KSA)}

Remaining undaunted by the economic challenges, most of the major economies have dived into the uncharted seas of the lockdowns, curfews and limitations of the movement of the population. KSA is the largest country in the Middle East, occupying approximately four-fifths of the Arabian Peninsula in km [2, 4], It has $>32$ million population of which approximately $63 \%$ are Saudis, while the remaining consists of working-age immigrants, originating mainly from India, Pakistan, Bangladesh and the Philippines [5].

Holiest place for one of the major religions - Islam, Saudi Arabia has experienced changes at various levels of society and its effect is well felt by each stratum who are undergoing these times of tests. KSA is also battered by the presence of the COVID-19 with about 223,327 positive cases as on June 9, 2020, which comprises of 60,131 active cases and 161,096 recovered ones [6]. Life has come to a standstill in once a vibrant society and people are feeling the brunt of this deadly virus.

With COVID-19 infection in one hand, this country is still battling with another viral infection known as MERS-CoV. Initially named as coronavirus or $\mathrm{nCoV}$, it was first reported in 2012 after genome sequencing of a virus isolated from sputum samples from a person who fell ill in a 2012 outbreak. The patient had reported flu-like respiratory illness. By July 2015, MERS-CoV spread over 21 countries, including Saudi Arabia [7]. After several years of MERS-CoV circulation, intensive efforts by the Saudi Ministry of Health $(\mathrm{MOH})$ has led to drastic improvement in infection control practices in health-care facilities nationwide. Most health-care workforce have a very high index of suspicion for MERS-CoV. Still the standardized and approved point of care testing for MERS-CoV is lacking, and hence the health care professionals continue to face challenges with respect to rapid detection and proper isolation of patients with MERS-CoV [8]. These challenges will now be faced by the whole global health community dealing with COVID-19. The symptomatic patients should now be tested for both MERS-CoV and COVID-19 simultaneously. With the ongoing MERS-CoV circulation in animal reservoir (dromedary camels) in the Arabian Peninsula and the continuing zoonotic spillover with $70 \%$ of cases resulting from nosocomial transmission [9], the risk of emergence of COVID-19 within the same community would be overwhelming for the health care infrastructure. This is a true concern with already rapid international spread to 25 countries outside China, especially with the ability of COVID-19 to spread from a totally asymptomatic person [8].

\section{An expatriate's view on Saudi government in combating COVID-19}

Being an expatriate has been challenging at various fronts, but after several years of stay, this society has been a comfort cushion. This welcoming atmosphere has widened even more in the current situation of global crisis. It is not only commendable the way the Saudi governance has managed to restrain the spread of the virus, but also worth appreciating the way the daily life needs have been available to everyone without any much perturbation.

Early lockdown with phased interventions at various levels and restricting the population movement depending upon density is a lustrous example of a bureaucracy which is socially responsible. Creating awareness amongst the community through recurring messages on mobile phones and innovative ideas to catch the attention of denizens has been quite effective tool initiated by Saudi MOH. Involvement is to such an extent that the ministers themselves have been circulating videos on hand washing techniques and their actions has been on the war front. Additionally, a continuous awareness to follow trustworthy sources and reliable guidance on social media and avoid myths and rumors is also being promoted.

The geographic location with deserts as definite borders around settlements seems to have smothered the disease to a great extent. Social distancing 
has been one of the cruxes in limiting the spread of the disease, with at least 3 feet of distance between individuals. Secondly, isolation through home quarantines and lockdowns with the cessation of almost all working activities has proved to be of immense importance in curbing of the viral dispersion. It is a pleasure to see around that the authorities in kingdom have left no stone unturned to achieve these goals. Numerous health care professionals and students have volunteered to fight the pandemic by setting up awareness camps and helping the screening procedure for people who visit the supermarkets and likewise.

Medical care of the affected people and quarantine facilities is as important as recovery and it is majorly attributed to the way the patient is handled. Kingdom has issued an order for free medical care and quarantine facilities which are world class. Rich with resources to handle the situation and plethora of personal protective equipment has complimented the care brilliantly. Nonetheless, the lessons learned by MERS-CoV circulations are well utilized by the Saudi government to keep the emerging pandemic and its severe outbreak under control. By promoting drastic impact measures they have managed to "flatten the curve' of the COVID-19 infection.

\section{COVID-19 and dental education}

Perhaps one of the most affected dimensions of the society is inarguably the educational sector. Thousands of schools and colleges have faced the backlash of closure and students all over have suffered in an unforgiving manner. Dentistry as a whole is not only a challenging field, but also demanding at various levels which is well supported by the fact that it needs one of the most grueling practical works including a balance between medical knowledge and dental services. Needless to say, any branch or field which needs this much of physical presence of the wards within the campus has been severely crippled.

It is a well-known fact that open communication among students, clinical teachers, and administrative staff enhances mutual trust and facilitates adequate cooperation [1]. But during the outbreak period, all kinds of aggregation of people should be avoided without hampering the learning process and this is exactly what the Saudi government did by initializing the distant learning through the smartboards to continue the learning process by the students. Online lectures, case studies, and problem-based learning tutorials are delivered by all the teaching faculties within the KSA. Existing smart devices and applications have already made it possible for students to listen to and review lectures whenever and wherever possible. These smart learning methods were made effective from the very early hours of COVID-19 outbreak within the Kingdom. Additionally, the students are continuously encouraged to engage themselves in self-learning, make full use of online resources, and learn about the latest academic developments. Other than this, continuous academic advising services are provided to those students who need any academic or psychological assistance.

Even though the distant learning has proved to be vital in stabilizing the learning experience, still it needs to be to proven in the long terms and it can be gauged only when we assess the outcomes through student experiences. There has been no dearth on delivering lectures and imparting knowledge through presentations via the electronic media, but laboratory sessions and patient experience has literally handicapped the overall course experience. The pandemic has deeply affected the delivery of services by the various health care specialties especially the dental professionals since they are at high risk for nosocomial infection and can become potential carriers of the disease. These risks can be attributed to the unique nature of dental interventions, which include aerosol generation, handling of sharps, and proximity of the provider to the patient's oropharyngeal region [10]. Although the significant limitation of clinical activities in the dental colleges is affecting the learning experience of the students but as a health care providers, it is of utmost importance to protect our patients, staff, family members, and society, and we must focus on preventing future outbreaks.

One of the perspectives of education which has definitely faced the repercussions of the lockdown has been examinations. It is one of the challenges which we need to explore as how to assess our students in this time of social distancing and curfews. There is still a long way to go for understanding this tool of education and its outcomes in an unprecedented way.

\section{Conclusion}

Every bird at the end of the day wants to return to its nest, wherein it finds the solace, unless a migrant one finds himself in a promised land. It is no wonder that almost third of population of Kingdom is an expat population who have over the years made this 
beautiful country as their home. And as we face lockdown and the COVID-19 illness has been giving a cold shoulder worldwide, there might be few places on earth which can be counted on your fingers to feel safe as the Kingdom. It is absolutely challenging to balance all the essential frontiers like social, physical and mental wellbeing of the residents, educational, health care and daily needs especially during the pandemic. Also, there has been no bigotry and discrimination in any form, in the delivery of various services by the Saudi government during this outbreak. Experiencing it first hand, it is needless to say, truly it is land o' the Leal and a wholesome place to be to face such a profane crisis.

\section{Conflict of interest}

None to report.

\section{References}

[1] Meng L, Hua F, Bian Z. Coronavirus disease 2019 (COVID19): Emerging and future challenges for dental and Oral Medicine. J Dent Res. 2020;99(5):481-7.
[2] Halepas S, Ferneini EM. A pinch of prevention is worth a pound of cure: Proactive dentistry in the wake of COVID19. J Oral Maxillofac Surg 2020 (In Press). Accessed https://doi.org/10.1016/j.joms.2020.03.036

[3] Bali RK, Chaudhry K. Maxillofacial surgery and COVID19, The Pandemic!! J. Maxillofac. Oral Surg 2020. Accessed https://doi.org/10.1007/s12663-020-01361-8.

[4] Robert AA, Zamzami MM. Stroke in Saudi Arabia: a review of the recent literature Pan African Medical Journal. 2014;17:14. doi:10.11604/pamj.2014.17.14.3015

[5] Al-Senani F, Al-Johani M, Salawati M, Alhazzani A, Morgenstern LB, Ravest VS, et al. An Epidemiological Model for First Stroke in Saudi Arabia. Journal of Stroke and Cerebrovascular Diseases 2020;29(1):104465. https://doi.org/10.1016/j.jstrokecerebrovasdis.2019.104465

[6] Accessed https://covid19.moh.gov.sa/

[7] Accessed https://www.who.int/csr/don/02-october-2014mers-austria/en/ "Disease Outbreak News". www.who.int. 8 October 2014.

[8] Barry M, Al Amri M, Memish ZA. COVID-19 in the shadows of MERS-CoV in the Kingdom of Saudi Arabia. Journal of Epidemiology and Global Health 2019. Accessed https://doi.org/10.2991/jegh.k.200218.003.

[9] Munster VJ, Koopmans M, van Doremalen N, van Riel D, de Wit E. A novel coronavirus emerging in China - key questions for impact assessment. N Engl J Med. 2020;382;692-94.

[10] Ather A, Patel B, Ruparel NB, Diogenes A, Hargreaves KM. Coronavirus Disease 19 (COVID-19): Implications for clinical dental care. Journal of Extension. 2020;46(5):584-95. 